\title{
Agency in the Writing Center: Examining the Importance of Student Autonomy in Higher Education
}

\author{
Ryan Rodriguez
}

\begin{abstract}
In college-level English courses, students often struggle to achieve satisfactory results in their writing. To remedy this, they seek help at campus writing centers, where a tutor helps them improve their writing skills and their academic performance. Yet, students experience tension between the classroom and the writing center that universities should seek to minimize. In my research, I discovered how different learning methods may either foster or suppress student autonomy. Further, I found that current methods-such as the course-embedded model for mitigating the tension between the writing center and the classroom-fail to empower the student. Using Rutgers University and its style of minimalist tutoring as a benchmark, I discuss the topics of autonomy and agency, student-led negotiation with authority, lack of academic motivation, and how we can bridge the pedagogical gap between the writing center and the classroom.
\end{abstract}

\section{Introduction}

Common on university campuses is the writing center, an institution for students in search of help with writing-based coursework. Assigned to tutors, students can intimately collaborate with a peer rather than their classroom professor. The writing center's aim is two-fold: first, to offer immediate support to students struggling in their English classes specifically, and second, to improve students' general compositional skills. Distinct from the classroom, traditional writing centers, such as those provided at Rutgers University, are supplemental resources used solely at the discretion of the student. A student may thrive in a writing course and still seek tutoring, or may fail paper after paper but still decline assistance. The writing center is an open invitation, advertising free help to all students in writing courses who need it and, more importantly, who actively want it.

What then becomes the subject of debate is how colleges can effectively implement writing centers. Such discourse heavily revolves around how differing approaches to tutoring impact students' improvement. However, the discussion insufficiently examines how the classroom and writing center environments noticeably differ, and to what extent the former might actually impede the latter. A writing center tutor's instructional style differs greatly from a student's 
primary professor. Further, whereas a writing center is an optional resource, the classroom is a non-negotiable, mandatory space. These distinct environments demonstrate how students operate differently in the presence and absence of authority.

Given these issues, how can we make these individualized, mentor-based writing centers function effectively alongside their classroom counterparts? In other words, how can universities minimize the tension students experience between the two environments? To explore this, I examined both existing literature and my own experiences as a tutor at the Plangere Writing Center at Rutgers University. I found that writing centers promote student autonomy in a way the classroom does not: the renewed sense of self-sufficiency the student receives generates significant motivation to succeed academically. And, while there are methods that bring both environments closer together, such as the course-embedded model, maintaining the distinct identity of each environment is crucial in giving students autonomy. A collaborative, peer-led learning process is one students will rarely encounter within traditional classroom settings. So, if the hierarchies present in the classroom are extended into the writing center, its benefits are eliminated. In this essay, I will indicate the distinctions between these two environments to help better understand how each functions in relation to the student. Furthermore, I will offer steps educators can take to bridge the gap between them.

Before moving forward, important clarifications are necessary. First, the following arguments pertain to the accepted standard of minimalist tutoring that has spread throughout higher education since Jeff Brook's (1991) initial introduction of the concept. This style rests on the student's ability to learn autonomously, as well as the tutor's ability to promote this autonomy. Second, my criticism of the classroom is not meant to be perceived as harsh; my intent is merely to highlight present flaws that inhibit student autonomy.

\section{Negotiating Autonomy and Authority}

Autonomy describes the extent to which a student experiences self-determined independence separate from outside influence. Troisi (2015) states that "people feel autonomous when they perceive their actions emanate from themselves rather than outside sources," and that "[f]eeling controlled by others rather than by the self undermines a person's sense of autonomy and her/his intrinsic motivation to perform tasks" (84). Passivity, on the other hand, occurs when students cannot explore avenues of personal interest. In such instances, instruction is severely limited in scope; it does not consider how students may want to learn but instead what they must learn. Unsurprisingly, this approach does not inspire motivation and interest in course material.

Van Lier (2008) offers a method of assessing students' relative passivity and autonomy. The proposed 1-6 scale ranges from the least ideal, passive, to most ideal, committed. "Committed" students "voluntarily enter into a debate with one another and create a collaborative agency event" (3). A "committed" student engages in the classroom and is fully invested in discussion. 
Of course, this is not limited to discussion-based classroom settings; it can be expressed in any environment where learners can interact with the instructor and the material being learnedwhether it be answering questions, collaborating with peers on assignments, communicating with an instructor during office hours, and so on. Most importantly, voluntary contributions demonstrate the student's direct engagement and genuine interest in their education.

Writing centers are designed to cultivate such voluntary participation. Thus, Rutgers and countless other higher education institutions implement a "minimalist" approach to tutoring. In a guidebook for Rutgers Writing Center tutors, the role of the writing center is described as such:

"Making the student do all the work" has become the mantra of what is called "minimalist tutoring," as first described by Jeff Brooks and as practiced at the Rutgers Writing Centers (and at practically every writing center across the country)... In the minimalist model, the writing tutor is a mentor, coach, or task master who guides students through the process of revision and helps keep them focused on the project at hand by breaking it down into smaller and more manageable tasks. (Goeller, Kalteissen 2008, 7)

This method necessitates student autonomy: if the student does not want to improve, the method falls apart. Yet this generally does not happen. Whether influenced by extrinsic motivations (e.g. good grades) or intrinsic motivations (e.g. personal development), a student who enrolls in tutoring already demonstrates a desire to improve. Thus, in my research, I found that students were willing to intimately engage with their assignments. When they committed to finding solutions for themselves, in direct collaboration with their tutor, they exhibited increased autonomy. The writing center allows the student to speak their mind and to question what they think is right or wrong.

However, I fear that students only experience such motivation during tutoring sessions, since the traditional classroom is less conducive to student autonomy. It works within the hierarchical system a university imposes, and there is little negotiation available. Thus, college-level curricula allow little to no opportunity to restructure the pedagogy, especially in larger classes that move through material quickly. Teachers often instruct what to do rather than giving students a range of choices; Rogoff et al. (2003) characterize it as "assembly-line instruction" with no community among students or active participation in the course material. Without a sense of choice, student passivity sets in. Such a setting does not permit the individualistic approach some students require. Ultimately, students suffer as a result: Freeman (2014) revealed the stunning disparity in academic success between learning in the traditional classroom versus an active learning environment, finding similar results across various disciplines (See Figs. 1 \& 2). 
These writing center and traditional classroom also differ in that the classroom has a much stronger authority figure than the writing centers. Healy notes, "The advantage tutors have over teachers in this enterprise is that even if students try to invest tutors with authority, tutors can resist that role, while teachers, as long as they give grades, have a harder time shedding their image as authority figures" (21). Additionally, Kail and Trimbur (1987) indicate that "peer tutoring based on collaborative learning taps into the network of mutual aid already based in student culture," including study groups, shared homework problems among friends, and so on (9). The level of comfort students experience due to tutor-student rapport affects student motivation. In managing classrooms, professors generally cannot be a personable guiding hand for each student, whereas tutors give the student a space where they are not talked down to or have to satisfy curricular expectations. Levels of comfort should be and are achieved in both settings, of course, but tutors find themselves in a favorable position: lacking true authoritative leverage, they exist on an even playing field with their students. This dynamic ultimately lets students be truer to themselves, searching for the approval of a role model instead of an authority figure.

The primary differences, then, between the writing center and classroom environment are the extent to which each encourages student autonomy, and the nature of each environment's authority. Where the instructor in a classroom is the singular, ultimate authority figure, the tutor is a peer with a guiding role. Where the classroom is a group of young adults under the professor's supervision, the writing center is a personal conference with a mutual interest in improvement. In the classroom setting, Healy (1993) writes that students "see themselves as acted upon rather than as agents of their own destiny, as subject to the authority of others rather than subjects of their own academic journey" (17). Conversely, Healy states that "Writing centers, as 'semi-autonomous' spaces, can serve as one of those forms of social organization through which students learn to negotiate issues of authority and learn to take more responsibility for their own learning" (18). While authority defines the classroom, cooperation defines the writing center. Where one cultivates student passivity, one fosters student autonomy. Students react differently depending on the environment they inhabit, and the writing center stimulates independent student thought to a degree the classroom does not. Writing centers allow students to determine the path of their writing, not under the supervision of an instructor, but with the guidance of a peer. Active participation in the writing process offers students the opportunity to act independently. Removed from passive instruction in the collective setting, they can fully engage in a one-on-one conversation that restructures the typical educational hierarchical structure. Thereby, they achieve autonomy.

It would be neglectful not to mention that the classroom is not entirely-as I have characterized it until this point - an environment disagreeable to effective education, nor is it a place where autonomy is perpetually nonexistent. As I stated previously, the writing center is a supplementary resource to the classroom whereas the classroom is vita/ to the learning process. Baringer and McCroskey (2000) reported that the immediacy experienced in a traditional classroom heightens appreciation for learning (178). Alexander Astin framed student 
involvement as the "physical and psychological efforts students put forth toward their academic experiences," ultimately defining the classroom as the major factor in a student's educational experience. With this in mind, Vincent Tinto noted that "students only formally experience education in the actual classroom" (Sidelinger 2010,88). There is no doubt then that the classroom affords a beneficial learning environment. Additionally, it develops an array of social skills. What becomes important is how to optimize its implementation, using resources like campus writing centers to improve the student's educational experience.

Unfortunately, students often experience tension between these two environments. I found that, when working with such authority figures as professors, students often were more concerned with pleasing their instructors than improving their writing. Rutgers sophomore A.P. related his personal account of tutoring. "Instead of taking the risk of arguing for a less favorable but more interesting side," he said, "I went into tutoring sessions asking the question, 'Do you think my professor will like this [phrase] or [that one] more?' This, in turn, changed the sessions from how to improve my writing so that I am able to do it on my own to both my tutor and I collaborating in ways to impress my professor." Rutgers sophomore K.D. similarly described tension between her professor and her tutor, feeling "hindered by the way [she needs] to balance the two" audiences. Clearly, the relationship between these environments must be more effectively mediated.

\section{Applying Student Autonomy: Columbia College}

Addressing the tension students experience between the writing center and the classroom begins with understanding that they operate differently despite their symbiotic relationship. Bridging the gap between the two entails improving the student's role in this cooperative relationship. And forging associations between them is not difficult by any means; it only requires the effort necessary to address the needs of students who visit the writing center. In On Location: Theory and Practice in Classroom-Based Writing Tutoring, Ottery and colleagues (2004) conducted a case study where tutors, teachers, and writing center consultants in Chicago's Columbia College collaborated with student learners in the writing process. Writing center consultants found that "[w]orking and meeting with instructors and the program coordinators offered tutors a chance to affect procedure and pedagogy, as they were able to provide [teachers] with information about how the students were reacting to the class" (Ottery et al. 2004, 63). This study shows how students become more or less forthcoming depending upon the power dynamic of their learning environment. The tutors could then communicate with their students' teachers, who gained insight they would not otherwise have access to. Instructors could use this new information to change how they address student's needs.

Conversely, writing centers at Rutgers, as is the case at many other universities, remain completely separate from the classroom. They may exist within the Rutgers English Department's Writing Program, and professors may advertise them as an optional resource; however, characterizing them as a direct extension of the classroom is inaccurate, since they do 
not directly consult with writing-based courses. Tutors do not communicate with students' professors, thus denying students the benefits demonstrated by the Columbia College study. One example, from Rutgers English professor Michael Duffy, recounts a time where this disconnect ultimately hurt a student's grade:

I had a situation with a student a few years ago who was allegedly "misled" by their tutor to the extent the tutor allegedly gave the student bad revision advice on their final 201 paper. The tutor's alleged advice made the student's claims more general and the student earned a grade they were not happy with. I should also say that the advice contradicted my comments on the student's draft. [However, t] "my tutor thought it was a good idea" isn't a good excuse because, like I said, the student must take ownership of their work-it's the student who earns the grade.

Of course, a student is responsible for the work they submit. The inherent problem here, however, is the contested loyalty students experience. A student meets with a Rutgers writing center tutor for a weekly, 80-minute session. Consequently, the rapport established between a tutor and a student builds, making it likely that students feel a closer attachment with their peer tutors than their professors. In the account above, a student bypassed explicit instruction from their professor and opted to heed the advice of their peer. While the fault still lies with the student, students should not be forced to choose which party to listen to. Adopting a Columbia College-like model eliminates contradictions between the professor and the tutor. Ottery, therefore, highlights the advantages of improved classroom-writing center communication. Additionally, Ottery's example of accessibility not only provides an actual pathway linking the writing center and the classroom, but also gives the student the individualistic attention they need in order to succeed academically.

\section{Current Discussion}

Much of the current discourse on writing center pedagogy examines the pros and cons of different tutoring approaches. These approaches include traditional, independent writing centers as well as other integrated models, such as classroom-based tutoring or the courseembedded model, which will be discussed in the next section. However, discourse fails to acknowledge how significantly classrooms directly impact tutors and the writing center. In other words, the conversation skews toward approaches to tutoring itself instead of questioning prominent external influences that impact the student. For instance, Corbett (2013) asks, "What can tutors do when they find themselves more closely attached to writing courses or curricula, to teacher expectations, [or] to student concerns?" (82) instead of asking about the student's external influences. Acknowledging these problems, rather than focusing exclusively on tutoring methods, gives a wider scope to the discourse-it considers the whole of the student rather than devoting all attention to the work alone. Similarly, Rutgers writing centers work to improve student writing skills without acknowledging why they are successful in the first place. But I believe this is an area in which Rutgers can enhance its approach-one that is already 
effective in its application of autonomy. Malavika Amenon, a tutor at Plangere Writing Center, believes that although a lot of tutoring is "common sense," how tutors are taught to help students is slightly flawed. She argues that tutor training "should give us a trial session to better prepare us," and that the internship "should be more hands-on in focusing how we can be effective tutors instead of learning how to write essays that reach teachers' expectations." As a tutor myself, I agree with her input. Granted, Rutgers' writing centers do functions exceptionally well. But although Rutgers's minimalist approach is effective in promoting autonomy, tutors and students alike need more guidance on how the writing center fits into the grander scope of learning.

Up to this point, I have argued that ignoring this significant facet to the writing-based tutoring model inhibits the effectiveness of our student aid. Without addressing this detail, tutors cannot fully understand the dynamics at play when a student feels tied between two different figures of authority, two different environments, and two different modes of thinking. Thus, I hope to elucidate conflicts between a pair of environments whose contradictory approaches place students at a disadvantage.

\section{The Course-Embedded Model}

Significant efforts have already been made to bring the classroom and writing center closer together. The proposed and widely accepted "course-embedded model" enjoys much praise (Carpenter, Whiddon, and Dvorak. 2014; Squibb, Mikkelsen 2016; Pagnac et al. 2014; Henry, Bruland, and Sano-Franchini 2011 ; Titus et al. 2014). But while its goal is to link classroom instruction and tutoring more intimately, the model ultimately caters to the classroom and relegates the writing center to a subsidiary role.

Building on Speigelman and Grobman's On Location (2004)-a foundational work for bridging classroom and writing center pedagogy-Carpenter and colleagues (2014) highlight the importance of layering writing center instruction within the classroom curriculum. They express displeasure with the traditional idea that the writing center and classroom should remain separate, stating, "course-embedded programs encourage teachers and tutors to work at the intersections of writing center and writing classroom spaces, creating unique opportunities and challenges for both parties" (3). Yet in doing so, the model establishes the student's curriculum as the main focus of the learning process. Thus, universities seize the writing center's role and appropriate it for the classroom. By doing so, this model supplants the autonomous space for students with aspects of the classroom that promote passivity. Kail and Trimbur (1987) write that "[t]he curriculum-based model operates through official channels," and rather than giving them full responsibility, it "makes peer tutors an extension of the writing program" (6). Building upon this, Healy (1993)-equating peer tutors in a course-embedded model to TAs-also argues why students deserve tutoring removed from the constraints of the classroom: 
[S]tudents [...] deserve direct support that is unmediated by the instructor, and that support can be better provided by a tutor than a TA-by someone, in other words, who is not affiliated with the course. By standing apart from the classroom, tutors provide a means of interrogating academic hierarchy. They provide an audience whose relationship to a student's writing is not governed by the same kind of "oughtness" as is the instructor's. (20)

Beholden to the course curriculum, the course-embedded writing center model takes away choice from the student. Students are forced to engage with tutoring rather than personally deciding if it is best for them. Students cannot possibly achieve Lier's "committed" status if their choice is taken from them.

Furthermore, the dynamic between students and tutors greatly changes, since the tutor is more invested in advancing classroom standards than establishing a rapport with the student. The tutor becomes synonymous with the classroom, and tutors' goals are torn between satisfying the needs of the instructor and the student. Such blurring of boundaries effectively erases the writing center altogether in favor of the classroom. Thus, Squibb's (2016) study concluded that the learning acquired from the course-embedded model instruction "did not translate to higher student achievement as represented by course grades and grade point average" (164). Yet the course-embedded model still receives praise. This discrepancy can be attributed to "chaos [that] sometimes clouds writing center administrators' ability to accurately account for the factors that contribute to the successes and failures of course-embedded writing support" (Webster, Hansen 2014, 52). Such chaos is caused by resistance to the implementation of the course-embedded model. Webster and Hansen rightfully point out that tensions exist between tutors and faculty when renegotiating their authoritative hierarchy, indicating that instructors may resist yielding administrative duties to tutors in this new dynamic. Amid current praise for this newer method of writing center tutoring, we lose sight of thoughtful critiques regarding such an ambitious model's application. As Andrea Lunsford (2000) reminds us, "[w]e shouldn't fool ourselves that creating new models of authority [...] is a goal we can hope to reach in any sort of straightforward way" (71).

The model also necessitates training tutors to exist within the curriculum of the writing course. When universities implement a course-embedded model, they must dedicate resources to ensure tutors meet certain standards. Tutors may be expected to "attend class and sometimes engage in teaching activities by conducting workshops, forming peer-response groups, and providing individual conferences during class time" (Carpenter, Whiddon, and Dvorak 2014, 4). While these expectations improve student learning, they also place an undue burden on tutors. Such a burden, on top of students' preexisting course load, discourages potential tutors from enlisting in the writing center's ranks. Rutgers University's current system of tutoring makes it virtually impossible for such a model to function; it is simply not feasible to require such an extreme investment from tutors. Ultimately, large universities like Rutgers cannot enlist student workers without interfering with their personal schedules, and it is one crucial reason 
separation of classroom and writing center are required. Difficult as it is to admit, it is not always about the methodology in theory but also its practicality.

\section{Conclusion}

The main takeaways from this discourse should be that the classroom and writing center function very differently, and that autonomy and independence are important for student success. To attain this goal, we must strike a balance between these two separate entities. The solution lies between two extremes: total separation and the course-embedded model. We should aim to open channels of communication between the writing center and the classroom, without letting the classroom supersede the supplementary writing center. To this end, tutors and teachers alike need to cultivate a dedicated commitment to student agency-practicing encouragement instead of coercion. Adopting Columbia College's method, or a variation on this approach, is an appropriate measure that links the classroom and the writing center in a firmer relationship. Importantly, primary teacher/secondary tutor correspondence forms a bridge while keeping them distinct. This is the direction we should take and one we hope to see more readily employed throughout (but not limited to) higher education.

Students feel frustrated obeying the education system. They struggle on the path toward success, and they often know they need additional aid to achieve their goals. So, it is up to educators to create stimulating environments that inspire students' drive to learn and respect their autonomy. Fostering this environment in the classroom is a challenge; but once it is achieved, the opportunity to effectively teach students presents itself with stunning clarity.

\section{References}

Baringer, Doreen K., and James C. McCroskey. "Immediacy in the classroom: Student immediacy." Communication education 49, no. 2 (2000): 178-186.

Brame, C. "Active learning." Vanderbilt University Center for Teaching (2016).

Brooks, Jeff. "Minimalist Tutoring: Making Students Do All the Work." Writing Lab Newsletter 15.6 (1991): 1-4. Print.

Carpenter, Russell, Scott Whiddon, and Kevin Dvorak. "Guest Editor Introduction: Revisiting and Revising Course-Embedded Tutoring Facilitated by Writing Centers." Praxis: A Writing Center Journal (2014).

Corbett, Steven J. "Negotiating Pedagogical Authority: The Rhetoric of Writing Center Tutoring Styles and Methods." Rhetoric Review 32 (1): (2013) 81-98.

Freeman, Scott, Sarah L. Eddy, Miles McDonough, Michelle K. Smith, Nnadozie Okoroafor, Hannah Jordt, and Mary Pat Wenderoth. "Active learning increases student performance in science, engineering, and mathematics." Proceedings of the National Academy of Sciences 111 , no. 23 (2014): 8410-8415. 
Goeller, M., and K. Kalteissen. "The task: A guide for tutors in the Rutgers writing center." (2008).

Hall, Emily, and Bradley Hughes. "Preparing faculty, professionalizing fellows: Keys to success with undergraduate writing fellows in WAC." The WAC journal 22 (2011): 21-40.

Healy, Dave. "A Defense of Dualism: The Writing Center and the Classroom." Writing Center Journal 14, no. 1 (1993): 16-29.

Henry, Jim, Holly Huff Bruland, and Jennifer Sano-Franchini. "Course-Embedded Mentoring for First-Year Students: Melding Academic Subject Support with Role Modeling, PsychoSocial Support, and Goal Setting. "International journal for the scholarship of teaching and learning 5, no. 2 (2011): n2.

Kail, Harvey, and John Trimbur. "The Politics of Peer Tutoring." WPA: Writing program administration 17 (1987): 5-12.

Lunsford, Andrea A. "Refiguring classroom authority." The ethics of writing instruction: Issues in theory and practice 4 (2000): 65.

Ottery, Jim, Jean Petrolle, Derek John Boczkowski, and Steve Mogge. "Writing and Reading Community Learning: Collaborative Learning among Writing Center Consultants, Students, and Teachers." In On Location: Theory and Practice in Classroom-Based Writing Tutoring, edited by Spigelman, Candace and Grobman, Laurie, 60-71. University Press of Colorado, (2005).

Pagnac, Susan, Shelley Bradfield, Cyndi Boertje, Elizabeth McMahon, and Gregory Teets. "An embedded model: First-year success in writing and research." Praxis: $A$ writing center journal (2014).

Rogoff, Barbara, Ruth Paradise, Rebeca Mejía Arauz, Maricela Correa-Chávez, and Cathy Angelillo. "Firsthand learning through intent participation." Annual review of psychology 54 (2003).

Sidelinger, Robert J. "College student involvement: An examination of student characteristics and perceived instructor communication behaviors in the classroom." Communication Studies 61, no. 1 (2010): 87-103.

Squibb, Sara Davidson, and Susan Mikkelsen. "Assessing the value of course-embedded information literacy on student learning and achievement." College \& research libraries 77, no. 2 (2016): 164-183.

Titus, Megan L., Jenny L. Scudder, Josephine R. Boyle, and Alison Sudol. "Dialoging a successful pedagogy for embedded tutors." Praxis: A writing center journal (2014).

Troisi, Jordan D. "Student management teams increase college students' feelings of autonomy in the classroom." College Teaching 63, no. 2 (2015): 83-89. Van Lier, Leo. "Agency in the classroom." Sociocultural theory and the teaching of second languages 163 (2008): 186.

Webster, Kelly, and Jake Hansen. "Vast potential, uneven results: Unraveling the factors that influence course-embedded tutoring success." Praxis: A writing center journal (2014). 